EASTERN REVIEW 2017, T. 6

Edyta Pietrzak

\title{
Współczesne teorie społeczeństwa obywatelskiego w świetle nowego materializmu
}

Analizując ideę społeczeństwa obywatelskiego, wkraczamy na „niepewny grunt tysiącletniej tradycji odwołującej się do societas civilis i koinonia politi$k e$ ". Obcujemy z ciągłością pojęcia wolnej politycznej samoorganizacji z pewnymi stałymi elementami normatywnymi, lecz także $\mathrm{z}$ wieloma jej przemianami, podczas których nigdy jednak nie zagubiono pojęcia "obywatelstwo”, ,polites”, „civis”, „citizen”, „citoyen”. Co więcej, w trakcie tych przemian obserwujemy poszerzanie się grupy posiadaczy praw obywatelskich ${ }^{1}$. Obywatelem może być tylko ten, kto ponosi odpowiedzialność (obojętnie, czy dzieje się to na poziomie wspólnoty, miasta, państwa, czy planety), a także ten, kto sprawuje władzę (i znów obojętnie, czy nad innymi, nad sobą, czy wraz z innymi). Dlatego zagadnienie społeczeństwa obywatelskiego jest zarazem tradycyjne, jak i nowoczesne.

Odwołując się do wspomnianych kategorii normatywnych, artykuł ten umiejscowić należy w obszarze myśli politycznej i filozofii polityki. Punktem wyjścia są tu teksty, a nie same problemy czy praktyczne przedsięwzięcia. Gdy patrzymy na coś z zewnątrz ${ }^{2}$, przyjmujemy punkt widzenia niedostępny dla biorących udział w akcji lub spektaklu. Jak zauważa Hannah Arendt, tylko obserwatorzy posiadają miejsce pozwalające im oglądać sztukę w całości, a wycofanie się poza grę jest warunkiem rozumienia jej sensu ${ }^{3}$. Dlatego podstawą do zrozumienia, wyjaśnienia i uzasadnienia przedstawionych tu zagadnień jest hermeneutyka Hansa Georga Gadamera ${ }^{4}$.

${ }^{1}$ R. Koselleck, Trzy światy obywatelskie? Wprowadzenie do porównawczej semantyki spoteczeństwa obywatelskiego w Niemczech, Anglii i Francji - zarys dziejów teorii, [w:] Rozmowy w Castel Gandolfo, red. K. Michalski, Warszawa-Kraków 1994, s. 112-113.

2 Słowo ,teoria” pochodzi wszakże od greckiego ,theata” (obserwatorzy).

${ }^{3}$ H. Arendt, Kondycja ludzka, Warszawa 2000, s. 139.

${ }^{4}$ H.-G. Gadamer, Prawda i metoda. Zarys hermeneutyki filozoficznej, Kraków 1993, s. 342-343. 
Przyjrzyjmy się zatem współczesnym teoriom ${ }^{5}$ społeczeństwa obywatelskiego, a za podstawę ich klasyfikacji przyjmijmy zasugerowane przez Reinharta Kosellecka kryterium rozszerzania się praw obywatelskich. Będą to więc teorie o wymiarze lokalnym, globalnym i transnarodowym. Posłużą nam one za odniesienie do tytułowej koncepcji nowego materializmu, będącej jedną z najciekawszych współczesnych prądów w humanistyce.

\section{Obywatelstwo lokalne}

Społeczeństwo obywatelskie miewa okresy popularności, kiedy dużo się o nim pisze i dyskutuje, oraz okresy, kiedy odchodzą w cień wypierane przez inne problemy polityczne. Najważniejszymi pojęciami teorii polityki drugiej połowy XX w. były „demokracja” i „sprawiedliwość”. „Obywatelstwo” było wobec nich tylko pojęciem pochodnym i sprowadzało się $\mathrm{w}$ znacznej mierze do posiadania praw $^{6}$. O ile więc pod koniec lat 70 . mówiono, że społeczeństwo obywatelskie wyszło z mody, tak już na początku lat 90 . za sprawą demokratycznych przemian w Europie Środkowo-Wschodniej było na ustach wszystkich, niezależnie od ich poglądów politycznych. Nastąpił tzw. zwrot deliberacyjny i teoretycy demokracji zaczęli interesować się procesem debaty publicznej (deliberation) kształtującym opinię publiczną. W tym samym czasie miał miejsce także zwrot w kierunku teorii obywatelstwa ${ }^{7}$ i z czasem zaczęło pojawiać się coraz więcej głosów optujących za stwierdzeniem, że obywatelstwo powinno odgrywać normatywną rolę w teorii polityki. Tematyka społeczeństwa obywatelskiego zaczęła być podejmowana zarówno przez liberałów, socjalistów, libertarian, komunitarystów, jak i feministki.

Dorota Pietrzyk-Reeves proponuje klasyfikację współczesnych teorii społeczeństwa obywatelskiego opartą na dwóch jego modelach: dwu- i trójdzielnym ${ }^{8}$. Model dwudzielny oparty na tradycji Hegla i Marksa oraz koncepcji liberalnej ujmuje społeczeństwo obywatelskie jako różne od państwa, ale obejmujące sferę ekonomii, będącą jego jądrem. Tu kluczowe są ujęcia Johna Keane'a, Darrowa Schectera i Ernesta Gellnera. Model trójdzielny opiera się na tradycji Alexisa de Tocqueville’a i Antonio Gramsciego, w których społeczeństwo obywatelskie

${ }^{5}$ Teorie w znaczeniu aspektowych teorii szczegółowych. Zob. M. Karwat, Rodzaje teorii w polityce, [w:] Czym jest teoria w politologii, red. Z. Blok, Warszawa 2011.

6 Jednakże to właśnie za sprawą procesu poszerzania się katalogu praw o prawa obywatelskie wieku XVIII, prawa polityczne w XIX w. i prawa społeczne w XX w., poszerzała się także grupa obywateli.

7 J. Dryzek, Souvereign Virtue: The Theory and practice of Equality, Cambridge 2000, cyt. za: W. Kymlicka, Contemporary Political Philosophy: An Introduction, Oxford 2002, s. 355.

${ }^{8}$ D. Pietrzyk-Reeves, Idea społeczeństwa obywatelskiego, Torun 2012, s. 268. 
oddzielone jest od państwa oraz od sfery ekonomii. Tworzą go koncepcje Jeana Cohena i Andrew Arato oraz Jürgena Habermasa.

Cechą wspólną drugiego modelu społeczeństwa obywatelskiego rozwijającego się w latach 90 . XX w. jest obszar jego funkcjonowania umiejscowiony między sferą polityczną a prywatną w postaci tzw. trzeciego sektora9 ${ }^{9}$ Kluczowym zagadnieniem jest tu kwestia umiejscowienia społeczeństwa obywatelskiego w ramach państwa lub poza nim. O ile stanowisko socjaldemokratyczne koncentruje się na tezie, że społeczeństwo obywatelskie nie może istnieć bez pomocy państwa, które musi regulować konflikty, naprawiać nierówności wynikające z siły i słabości różnych grup, zapobiegać wykluczeniu i działać na rzecz wolności politycznej i pluralizmu, to stanowisko związane z liberalizmem opiera się na autonomii i wolności jednostek oraz obronie ich przed władzą urzędników państwowych. Zaś w interpretacji komunitariańskiej społeczeństwo obywatelskie to wspólnota, w której istnieją afektywne relacje, wspólne wartości, normy, historia i tożsamość oraz nastawienie na realizację dobra wspólnego, a także wysoki poziom wrażliwości na potrzeby członków grupy ${ }^{10}$.

W dobie ponowoczesności metafora trzeciego sektora powoli ulegała rozmyciu. Społeczeństwo obywatelskie przestało być już mediatorem między kapitałem a suwerennością. Zostało wchłonięte przez państwo, ale na skutek tego pojawiło się mnóstwo elementów koordynowanych dotąd przez społeczeństwo obywatelskie. Jednocześnie zostało także wchłonięte przez struktury intymne, jak rodzina, seksualność czy płeć, na skutek czego w życiu prywatnym pojawiło się szereg elementów dotąd wiązanych z władzą. Przestało funkcjonować pojęcie społeczeństwa obywatelskiego jako zorganizowanego systemu administrowania na rzecz mobilności, plastyczności i nieustannego różnicowania się gatunku ludzkiego ${ }^{11}$.

${ }^{9}$ Według Ralpha Dahrendorfa charakteryzuje się on istnieniem niesterowanych przez państwo ani inny ośrodek organizacji i instytucji jako organów woli ludu. Ale już, jak zauważa Charles Taylor, istnieje także tam, gdzie wolne stowarzyszenia pod kuratelą władzy państwowej, a, jak pisze Michael Walzer, nawet więcej, bo także jako przestrzeń niewymuszonego ludzkiego stowarzyszenia, sieć stosunków nawiązanych w imię rodziny, wiary, interesu oraz ideologii, by tę przestrzeń wypełnić. Zob. R. Darendorf, Zagrożone społeczeństwo obywatelskie, [w:] Europa i spoleczeństwo..., s. 7; Ch. Taylor, Kiedy mówimy: spoleczeństwo obywatelskie [w:] ibidem, s. 59; M. Walzer, Spór o społeczeństwo obywatelskie, [w:] Ani książę, ani kupiec. Obywatel. Idea społeczeństwa obywatelskiego w myśli wspótczesnej, red. J. Szacki, Kraków 1997, s. 7.

${ }^{10}$ Szczególną rolę w krzewieniu współczesnej idei społeczeństwa obywatelskiego mają amerykańcy komunitaryści tacy jak Charles Taylor, Amitai Etzioni, Michael Walzer, Michael Sandel, Alisadair MacIntyre, którzy pokazali, że liberalny obywatelstwo jest z powiązane z liberalnymi prawami jednostki, ale też z ideami przynależności do konkretnej wspólnoty.

${ }^{11}$ P. Dybel, S. Wróbel, Granice polityczności. Od polityki emancypacji do polityki życia, Warszawa 2008, s. 177. 


\section{Obywatelstwo globalne}

Wraz z tym, jak współczesna demokracja stawała się coraz bardziej „kosmopolityczna, obywatelstwo nie mogło już być budowane tylko w oparciu o perspektywę narodową. Powstały więc ponadnarodowe koncepcje obywatelstwa. O ponadnarodowych sieciach, organizacjach i relacjach napisano tak wiele, że teksty te w jakimś sensie wywołały ideę globalnego społeczeństwa obywatelskie$\mathrm{go}^{12}$. Jest ona udokumentowana w roczniku „Global Civil Society” wydawanym przez London School of Economics, redagowanym przez Mary Kaldor, Helmuta Anheiera i Marlies Glasius. Do najważniejszych publikacji na ten temat należą: Toward a Global Civil Society Micheala Walzera ${ }^{13}$, Global Community: The Role of International Organizations in the Making of the Contemporary World Akiry Iriye ${ }^{14}$, One World: The Ethics of Globalization Petera Singera ${ }^{15}$, Global Civil Society? Johna Keane'a ${ }^{16}$, będąca próbą skonceptualizowania globalnego modelu społeczeństwa obywatelskiego, The Global Civil Society. An Answer to War Mary Kaldor ${ }^{17}$ czy praca From Empire to Community: A New Approach to International Relations Amitaia Etzioniego ${ }^{18}$. Trzeba tu także wspomnieć dzieła Ürlicha Bec$\mathrm{ka}^{19}$ oraz Manuela Castellsa ${ }^{20}$ czy Davida Helda ${ }^{21}$.

Przyczynami powstania globalnego społeczeństwa obywatelskiego i zarazem najbardziej wyrazistymi cechami je charakteryzującymi są ryzyko i technologia. Powszechne odczuwanie ryzyka ${ }^{22}$, które jako najbardziej demokratyczne ze współczesnych zjawisk, opisane przez Ü. Becka w słynnym Społeczeństwie

12 P. Seters, Aproaching Global Civil Society, [w:] Critical Mass, The Emergence of Global Civil Society, eds. J.W. Walker, A. Thompson, Waterloo 2008, s. 32.

${ }^{13}$ M. Walzer, Toward a Global Civil Society, New York 1995.

${ }^{14}$ Zob. A. Iriye, Global Community: The Role of International Organizations in the Making of the Contemporary World, Berkeley 2002.

15 Zob. P. Singer, One World: The Ethics of Globalization, New Haven 2002.

16 Zob. J. Kean, Global Civil Society?, Cambrigde 2003.

17 Zob. M. Kaldor, The Global Civil Society. An Answer to War, Cambridge 2003.

18 Zob. A. Etzioni, From Empire to Community: A New Approach to International Relations, New York 2004

${ }_{19}$ Zob. Ü. Beck, E. Beck-Gernsheim, Miłość na odległość. Modele życia w epoce globalnej, Warszawa 2013; Ü. Beck, Spoleczeństwo ryzyka. W drodze do innej nowoczesności, Warszawa 2002; idem, Władza i przeciwwładza w epoce globalnej. Nowa ekonomia polityki światowej, Warszawa 2005.

${ }^{20}$ Zob. M. Castells, Sieci oburzenia i nadziei. Ruchy społeczne w erze internetu, Warszawa 2013; idem, Siła tożsamości, Warszawa 2008; idem, Społeczeństwo sieci, Warszawa 2007; idem, The Power of Identity, Oxford 1997; idem, The Rise of Network Society, Oxford 2000.

${ }^{21}$ Zob. Global Transformations. Politics, Economics and Culture, ed. D. Held, Cambridge 1999; D. Held, Global Covenant. The Social Democratic Alternative to the Washington Consensus, Cambridge 2004.

${ }^{22}$ Zob. Ü. Beck, Spoteczeństwo ryzyka... 
ryzyka. W drodze do innej nowoczesności, oplata cały świat. Odczucie to sprzyja także wytwarzaniu się wspólnoty ryzyka i wspólnemu podejmowaniu pracy na rzecz jego eliminacji lub przynajmniej oswojenia go. Technologia natomiast spowodowała, że pojawił się nowy model współczesnego społeczeństwa ${ }^{23}$. Czegokolwiek by nie powiedzieć o globalnym społeczeństwie obywatelskim, nie istniałoby ono bez sieci. I choć trudno wyobrazić sobie społeczeństwo pozbawione granic, to sieci ich nie mają, są otwarte, rozszerzają się i kurczą w zależności od interesów i wartości. Skupiająca się wokół sieci społeczna dynamika prowadzi do zaniku społeczeństwa jako stabilnej formy społecznej organizacji ${ }^{24}$.

Dlatego też globalne społeczeństwo to ogół struktur i działań mieszczących się na przecięciu sfery państwa, sfery prywatnej i sfery gospodarczej, których celem nie jest rządzenie państwem ani osiąganie zysku ekonomicznego, lecz wpływ na władze i jej monitorowanie. W odróżnieniu od wcześniejszych modeli społeczeństwa obywatelskiego, które odwołują się do władzy lokalnej, tutaj władza pojmowana jest globalnie. Trwałe struktury zastępowane są tu przez luźne koalicje i spontaniczne ruchy nieformalne. Aktorzy globalnego społeczeństwa obywatelskiego z jednej strony zdani są na państwa, a z drugiej są głównymi przeciwnikami państw i koncernów ekonomicznych, gdyż rozporządzają siłą „globalnego klienta”. Mobilizacja globalnego społeczeństwa polega na dostarczeniu informacji przez organizacje społeczne korzystające z mediów spoza głównego nurtu i interentu oraz wzbudzeniu oburzenia. Globalne społeczeństwo jest wielopoziomową, gęsto powiązaną przestrzenią istniejącą w relacjach i dynamice społecznej. Charakteryzuje je pokojowe nastawienie i organizowanie się przeciwko przemocy i nietolerancji, dążenie do zapewnienia wolności, równości i solidarności za sprawą organizacji pozarządowych, które funkcjonują we wszystkich zakątkach świata oraz odpowiedzialność za świat ${ }^{25}$. Tak jak inne modele, ten typ społeczeństwa obywatelskiego koncentruje się wokół kategorii arystotelesowskiego dobra wspólnego. Umiejscawiane jest ono jednak już nie w perspektywie polis, ale perspektywie kosmos.

Przedstawione tu teorie globalnego społeczeństwa obywatelskiego poddane zostały ostrej krytyce. Głównym jej powodem był ich normatywny charakter. Odnosiły bowiem się bardziej do pozytywnej wizji niż do stanu faktycznego. Pierwszym argumentem tych ataków był zarzut, że opisują czysto teoretyczną, niespotykaną $\mathrm{w}$ życiu politycznym kategorię.

${ }^{23}$ Model następujący po modelu M. Webera przedstawiającym społeczeństwo jako mechanizm biurokracji czy modelu R. Ritza opisującym społeczeństwo jako restaurację McDonalds.

${ }^{24}$ M. Castells, Władza komunikacji, Warszawa 2013.

${ }^{25}$ Przykładami takiego działania był amerykański ruch Occupy Wall Street czy hiszpański ruch Indignados z $2011 \mathrm{r}$. 


\section{Obywatelstwo transnarodowe}

W związku z krytyką teorii globalnego społeczeństwa obywatelskiego, a także wydarzeniami politycznymi jak np. kryzys finansowy w 2008 r. czy kryzys migracyjny spójne wizje globalnego społeczeństwa zmuszeni jesteśmy odłożyć. Teoretycy nie odeszli jednak zupełnie od koncepcji obywatelstwa i ich wpływu na realne życie polityczne. Dostosowali je natomiast do panujących warunków. Już w pierwszej dekadzie XXI w. pojawiły się w związku z tym propozycje widzenia społeczeństwa obywatelskiego w optyce transnarodowej ${ }^{26}$. Nawet w sytuacji kryzysowej zmuszeni jesteśmy bowiem do współdziałania. Za sprawą zmian, jakie wprowadziła w nasze życie globalizacja, nie ma już możliwości odgrodzenia się od świata w lokalnych państwach narodowych. Konieczne jest współdziałanie.

Za podmioty transnarodowe uznaje się pozapaństwowych, pozarządowych, niesuwerennych i nieterytorialnych uczestników, których działalność świadomie przekracza granice państw i wywiera wpływ na stosunki wewnątrzpaństwowe i międzynarodowe ${ }^{27}$. Różnego rodzaju organizacje obywateli wykraczające w swych działaniach poza obszar granic narodowych, zorientowane wokół wspólnych celów, interesów bądź projektów, zalicza się do transnarodowej działalności obywatelskiej ${ }^{28}$. Transnational networks to jednak również nieformalne powiązania, tj. łańcuchy migracyjne, organizacje religijne czy działalność przestępcza ${ }^{29}$. Rozkwit sieci transnarodowych jako rodzaju aktywności w społeczeństwie obywatelskim koresponduje z modelem deliberatywnej demokracji, zakładającej autonomiczność i komunikację jako podstawy wypracowywania wspólnych działań w sferze publicznej. Efektem takiego modelu integracji jest rozumienie instytucji i zarządzania na szczeblu wspólnoty w kategoriach transnarodowych (transnational governance).

${ }^{26}$ Idea transnarodowości, jaką znamy obecnie, pojawiła się w naukach społecznych już na początku lat 70. XX w. jako reakcja na rosnącą złożoność rzeczywistości społeczno-kulturowej, na hybrydyczność i wielość przynależności poszczególnych jednostek. W najszerszym rozumieniu odwołuje się do wspólnoty kulturowej, powiązań komunikacyjnych i regulacji społecznych przekraczających granice państw narodowych i zachodzi w wymiarach: ekonomicznym, polityczno-prawnym, społecznym czy kulturowym jako wielolokalny proces (plurilocal) odbywający się na różnych poziomach geograficznych: lokalnym, mikroreginalnym, narodowym, makroregionalnym i globalnym. „Jednocześnie termin zwraca uwagę na to, co neguje, czyli znaczenie tego co narodowe”. Zob. U. Hannerz, Powiazania transnarodowe. Kultura, ludzie, miejsca, Kraków 2006, s. 19.

${ }^{27}$ A. Dumała, Uczestnicy transnarodowi - podmioty niezależne czy kontrolowane przez państwa?, [w:] Państwo we wspótczesnych stosunkach międzynarodowych, red. E. Haliżak, I. Popiuk-Rysińska, Warszawa 1995, s. 196.

${ }^{28}$ Por. J. Baylis, S. Smith, Globalizacja polityki światowej. Wprowadzenie do stosunków międzynarodowych, Kraków 2008, s. 24.

${ }^{29}$ E. Moddelmog-Anweiler, Rooted cosmopolitans - Idea tożsamości transnarodowej i znaczenie granic w Europie, [w:] Granice wewnętrzne i zewnętrzne Unii Europejskiej pomiędzy otwartościq a izolacją, red. J. Jańczak, M. Musiał-Karg, Poznań 2011, s. 2. 
Do najbardziej znanych pozycji wykorzystujących termin społeczeństwa transnarodowego należą prace Creating Credibility: Legitimacy and Accountability for Transnational Civil Society ${ }^{30}$ oraz Transnational Civil Society: An Introduction $^{31}$ L. Davida Browna. Jak również The Third Force: The Rise of Transnational Civil Society Ann Florini ${ }^{32}$. Brown pisze o transnarodowej arenie, która pojawiła się wraz z rozwojem globalizacji. Arena ta daje możliwości rozwoju organizacji pozarządowych, a tym samym społeczeństwa obywatelskiego, których nigdy wcześniej nie było. By bowiem rozwiać lokalne problemy, nie wystarcza dziś już działać lokalnie, a trzeba wznieść się na poziom ponadlokalny i ponadnarodowy.

Czym różni się teoria transnarodowa społeczeństwa obywatelskiego od globalnej? Nie odwołuje się do idei wspólnoty konstruowanej ponad podziałami, a raczej oparta jest na wielości i różnorodności oraz przypomnieniu idei państwa narodowego i tożsamości narodowej podmiotów. Pozostaje ona, jak sama nazwa wskazuje, na poziomie relacji między nimi. Co więcej, o ile globalne społeczeństwo obywatelskie to raczej kategoria ponadhierarchiczna i ponadstrukturalna, bezgraniczna wspólnota, o tyle określenie „transnarodowy” stosowane jest w kontekście ruchów społecznych, organizacji lub instytucji, a przede wszystkim sieci oraz aktorów sfery publicznej. Odnosi się ono zatem bardziej do praktyki polityczno-prawnej aktorów transnarodowych.

\section{Nowy materializm}

Choć doświadczamy w ostatnich latach kryzysu obywatelstwa powiązanego z kryzysem demokracji, pojawiają się jednak nowe koncepcje filozoficzne, które problem obywatelstwa i społeczeństwa obywatelskiego stawiają w nowym świetle. Jedną z nich jest nowy materializm.

Najbardziej znaną, oprócz Rossi Braidotti ${ }^{33}$, która zapoczątkowała ten nurt, i Manuela DeLandy'ego ${ }^{34}$ czy Quentina Meillassoux ${ }^{35}$, twórczynią nowego ma-

${ }^{30}$ Zob. Transnational Civil Society: An Introduction, eds S. Batliwala, L.D. Brown, Bloomfield CT 2006.

${ }^{31}$ Zob. L.D. Brown, Creating Credibility: Legitimacy and Accountability for Transnational Civil Society, Bloomfield CT 2008.

${ }^{32}$ Zob. The Third Force: The Rise of Transnational Civil Society, ed. A. Florini, Tokyo-Washington 1999.

${ }^{33}$ R. Braidotti jest autorką terminu, choć swoją teorię nazywa materialno-realistycznym lub posthumanistycznym, witalistycznym feminizmem. R. Braidotti, Podmioty nomadyczne. Ucieleśnienie i różnica seksualna w feminizmie współczesnym, tłum. A. Derra, Warszawa 2009; eadem, Po czlowieku, tłum. J. Bednarek, A. Kowalczyk, Warszawa 2013.

${ }^{34}$ M. DeLanda, Philosophy and Simulation: The Emergence of Synthetic Reason, LondonNew York 2011.

${ }^{35}$ Q. Meillassoux, After Finitude. An Essay on the Necessity of Contingency, New York 2008; Q. Meillassoux, The Number and the Siren, New York 2012. 
terializmu, zwanego też feministycznym materializmem czy postkonstruktywizmem, jest Karen Barad, doktor fizyki pól kwantowych, filozofka, historyczka świadomości i profesor Feminist Studies Uniwersytetu Kalifornijskiego w Santa Cruz. Łączy ona teorię fizyki kwantowej ze studiami nad nauką i technologią, studiami kulturowymi i filozoficznymi.

Jako bezpośrednią bazę dla swojego ontologicznego ujęcia K. Barad przyjmuje ustalenia fizyka-filozofa Nielsa Bohra znane jako ,interpretacja kopenhaska”. Według N. Bohra, podstawową jednostką badań epistemologii i nauki nie są niezależne obiekty (rzeczy), lecz „fenomeny” produkowane w toku praktyki poznawania jako dynamiczna relacyjność. Konsekwentnie, obiekty nie są pierwotne wobec procesów, którym podlegają, raczej pojawiają się poprzez nie i w ich toku. Wynik tych procesów nie prowadzi do zamkniętych indywidualnych bytów - choć określonych, jednak nigdy kompletnie zdeterminowanych. Czyli, rzeczywistość jest wyłaniającą się materialnością, staje się, świat jest trwającym otwartym procesem materializowania się, poprzez który materia sama dochodzi do znaczenia i realizuje różne formy swych sprawczych możliwości ${ }^{36}$.

36 Podstawą dla powyższych epistemologicznych wniosków był dla N. Bohra przeprowadzony w późnych latach 20. XX w. (a zrealizowany dopiero w latach 90 . XX w.) myślowy eksperyment tzw. podwójnej szczeliny. N. Bohr ustalił, że wszystkie cząstki kwantowe (fotony, elektrony, atomy) wykazują własności bądź falowe, bądź korpuskularne - w zależności od rodzaju przeprowadzonego eksperymentu, rodzaju apparatusa (przyrządu, urządzenia). Gdy przepuszczać elektrony przez płytkę z dwoma szczelinami, po przejściu przez nią, na ekranie tworzą one obraz fali; elektrony (wyobrażone jako cząstki), podlegając dyfrakcji i dając inferencyjny wzór, zachowują się jak fala. Kiedy natomiast zamontujemy dodatkowo przed płytką czytnik pomiarowy - urządzenie ustalające, przez którą szczelinę przechodzi elektron, przez górną lub dolną - wówczas elektrony, uderzając w ekran, tworzą wzór rozrzuconych punktów, zachowują się więc jak cząstki. Ten eksperyment skłonił N. Bohra do przyjęcia interpretacji o czynnym udziale apparatusa w wynikach pomiarów. Apparatus wpływa na proces przestrzenno-czasowych granic obiektów (ich pozycję i pęd - momentum), które nie mogą być mu przypisane przed obserwacją. Mierzący apparatus „tnie” splątania pomiędzy obserwującym sprawcą a obserwowanym obiektem (inaczej za każdym razem). Według N. Bohra, to spostrzeżenie dowodzi „esencjonalnego błędu reprezentacjonizmu", w ramach którego już na wstępie zakłada się obecność wewnętrznych cech obserwowanych obiektów. Przyjęcie abstrakcyjnych pojęć „pozycja” i „pęd” ma tylko sens wówczas, kiedy do badań używa się twardego oprzyrządowania; nie są one cechami niezależnie istniejących badanych obiektów. I to nie „zaburzenia” możliwości jednoznacznego odczytu powodowane pomiarem (albo pozycja albo pęd, nigdy oba wymiary równocześnie), jak zawyrokował uczeń i współpracownik N. Bohra, Werner Heisenberg i który na tej podstawie sformułował „zasadę nieoznaczoności”, a właśnie współoddziaływanie tych elementów. Pomiar „pozycji” i „pędu” przy użyciu przyrządu nie może być przypisany do jakiegokolwiek istniejącego niezależnie, abstrakcyjnego obiektu, ale jest cechą fenomenu - immanentnej nierozdzielności obserwowanego obiektu i sprawców (agents) obserwacji. Dwoista falowo-korpuskularna natura (paradoks cząstka-fala) jest powszechną właściwością materii. N. Bohr uznawał wagę ,zasady nieoznaczoności” W. Heisenberga, jednak w miejsce wniosku o kresie naszych możliwości dokładniejszego poznania („nieoznaczoności” czy „,niepewności”), przyjął „zasadę indeterminizmu". Zob. E. Hyży, Dzielenie się światem. Nowy feministyczny realizm w ujęciu Karen Barad, s. 9-10, https://www.academia.edu/28271247/Dzielenie_si\%C4\%99_\%C5\%9Bwiatem.Nowy_feministyczny_realizm_w_uj\%C4\%99ciu_Karen_Barad.pdf(dostęp 15.10.2016). 
Swoją koncepcję K. Barad określa mianem „etyko-onto-epistemologii”, likwidującej granice między tym co ludzkie i nieludzkie, materialne i dyskursywne, uznając współ-konstytutywność tych wszystkich sfer wobec rzeczywistości. K. Barad korzysta m.in. z teorii Donny Haraway, Judith Butler, Elizabeth Grosz, Michaela Foucaulta. Wskazuje jednak na potrzebę zmian w postmodermistycznym i poststrukturalistycznym paradygmacie, który przyznawał zbyt dużą władzę językowi i semiotycznym interpretacjom kultury.

Nowy materializm to posthumanistyczny i antyantropocentryczny nurt, odmienny wszakże od materializmu marksistowskiego. Zwraca się do materii jako do czynnika aktywnego i przyznaje jej szczególny rodzaj sprawstwa (agency). I to w relacji nie tylko do człowieka czy świata ożywionego, ale do wszystkich aspektów bytu ${ }^{37}$.

K. Barad rozwija relacyjną ontologię ,sprawczego realizmu” (agential realism $)^{38}$, w której wykracza poza podziały dyscyplin naukowych i łączy ustalenia nauk przyrodniczych z naukami społecznymi i z filozofią. Proponuje podejście oparte na ścisłej więzi między dyskursywnością i materialnością, będące wynikiem stałego dynamicznego procesu materializowania świata (mattering) ${ }^{39}$.

W zachodniej filozofii zdolność sprawstwa tradycyjnie służy odróżnieniu człowieka od reszty natury i występuje w różnych kontekstach osobowości - racjonalności, intencji, woli, autonomii. Ogranicza się więc wyłącznie do człowieka. K. Barad nie zgadza się z tym poglądem i stara się doprowadzić do uznania także sprawczej funkcji materii. Jej zdaniem, rozdział pomiędzy sprawcą i sprawstwem, dokonującym i dokonanym musi być zlikwidowany już na ontologicznym poziomie $^{40}$. Zgodnie ze sprawczym realizmem, sprawstwo nie przynależy już do ludzkiej orbity, lecz jest działaniem/byciem w intra-akcji, nie jest atrybutem, ale trwającym re-figurowaniem świata. Nie mamy szczególnej ontologicznej pozycji w świecie, jesteśmy jego częścią.

Tym samym nowy materializm wiąże się z przyjęciem ontologicznego monizmu, czyli z przyznaniem aktywności i szczególnego rodzaju sprawstwa materii, odrzuceniem dualizmu ciało-umysł, uznaniem, że wszystkie rzeczy organiczne i nieorganiczne są konstytuowane z tych samych elementów, a także z odrzuceniem antropocentryzmu za sprawą podważania uprzywilejowania pozycji człowieka w świecie. Ontologiczna baza nie składa się tu z oddzielnych rzeczy, ale jest raczej siecią relacji, w których i poprzez które wyłaniają się różnorodne obiekty. Materia jest sprawczą ,substancją-w-jej-intra-akcyjnym-stawaniu się"41.

37 Ibidem, s. 3.

38 Zob. K. Barad, Meeting the Universe Half Way, Quantum Physics and the Entanglement of Matter and Meaning, New York-London 2007.

39 K. Barad, Diffracting diffraction: Cutting together-apart, „Paralax” 2014, no. 20(3), s. 174.

40 E. Hyży, Dzielenie się..., s. 8.

${ }^{41}$ K. Barad, Posthumanist performativity: Toward an understanding of how matter comes to matter, ,Signs: Journal of Women in Culture and Society” 2003, no. 28, s. 817. 
Dlatego etyka K. Barad to etyka bycia w świecie, etyka odpowiedzialności ${ }^{42}$, umożliwienia odpowiedzi innego/innemu. Odpowiedzialność jest już zawsze integralna wobec intra-aktywnego stawania się świata. Jest to odpowiedzialność $\mathrm{z}$ innymi. Nie jest kalkulacją do przeprowadzenia, a relacją integralną $\mathrm{z}$ trwającym intraaktywnym stawaniem i nie-stawaniem się ${ }^{43}$. Należymy do świata - nie ma podziału na wewnątrz i zewnątrz. Jesteśmy też obarczeni moralną odpowiedzialnością za swój rozwój polityczny i wszystko, co uczyniliśmy bądź czego nie uczyniliśmy. Nie da się bowiem żyć tylko dziś. Przeszłość jest częścią rzeczywistości, tak jak przyszłość.

\section{Nowy materializm i społeczeństwo obywatelskie}

Dlaczego nowy materializm może być istotny dla społeczeństwa obywatelskiego? I jakie wynikają z niego konsekwencje? W działaniach politycznych, a za takie uznajemy przejawy funkcjonowania społeczeństwa obywatelskiego, tradycyjnie sprawczość w postaci czy to lexis, czy to praxis przypisana była ludziom wpływającym na rzeczywistość, rozwiązującym problemy, głosującym, debatującym lub podejmującym decyzje. Aktywności te łączone zawsze były z racjonalnością i refleksyjnością człowieka i dlatego człowiek jako jedyny pośród innych bytów określany był mianem zoon politikon.

Tymczasem dla K. Barad ta wyjątkowość przypisywana ludzkiemu sprawcy potrzebuje zwrotu i tego, by zaczęto ją postrzegać w szerszych kontekstach, od których nie może się ona i nie powinna oddzielać. Nowy materializm podważa więc ,antropocentryczną pychę" zawartą w tradycyjnym rozumieniu funkcji polityczności jako ludzkiej wyjątkowej zdolności transformowania i kształtowania świata ${ }^{44}$.

To, co najciekawsze w propozycji K. Barad dla koncepcji społeczeństwa obywatelskiego, to rozciągnięcie odpowiedzialności także na obszary pozaspołeczne, pozaludzkie, a nawet poza świat ożywiony. Możemy więc na jej koncepcję spojrzeć jako na poszerzającą dotychczasowe rozumienie społeczeństwa obywatelskiego, od jego wymiaru lokalnego, przez transnarodowy i globalny aż do wymiaru pozamaterialnego. W związku z tym pojawia się pytanie: Jak traktować te obszary? Na samym początku tego tekstu za Reinhartem Kosel-

${ }^{42}$ Inne określenie K. Barad to ,etyka materializowania” (ethics of mattering), czyli etyka zaangażowana w przerwanie obojętności (ethics committed to the rupture of indifference). K. Barad, On touching - the inhuman that therefore $i$ am, differences, „A Journal of Feminist Studies” 2012, no. $23 / 3$, s. 216 .

${ }^{43}$ K. Barad, Meeting the Universe Half Way..., s. 264.

${ }^{44}$ E. Hyży, Dzielenie się..., s. 16. 
leckiem uznałam, że obywatelem jest ten, kto posiada odpowiedzialność i sprawuje władzę. O ile, w myśl nowego materializmu, możemy przypisać materii sprawczość, to, czy i w jaki sposób miałaby też być przypisana materii władza? Czy w sensie praw fizyki, którym wszystko podlega? Czy „złośliwości rzeczy martwych"?

Ze względu na włączenie pojęcia sprawczości materii do etyki i polityki przepracowania wymaga też pojęcie odpowiedzialności. W świetle wszystkiego, co tu napisano, staje się tu ona troską o relacje ze światem. Odpowiedzialność jest immanentnie związana z procesami stawania się, które zachodzą poprzez odpowiedź innym. Takie pojęcie politycznej odpowiedzialności implikuje solidarność opartą już nie wyłącznie na bliskości i podobieństwie, ale na byciu-w-tym-razem. Polityczność to już nie sprawa wyboru i decyzji, ale powiązań, spotkań i włączania; jest wyobrażeniem sobie sprawstwa politycznego jako transformującej siły osiągania ,przyjaznego świata, świata opartego na wartościach współrozwoju i wzajemności” ${ }^{45}$. A zatem, nie tylko ,ja” jestem politycznym aktorem, ale wszystko, $\mathrm{z}$ czym jestem w kontakcie, włączając w to pokarm, wodę, odpady czy ziemię, staje się aktorem politycznym.

Odpowiedzialność szczególnie istotna jest w aspekcie zagrożeń ekologicznych oraz wspomnianych już wcześniej powiązań globalnych, gęsto przenikających wszystkie obszary współczesnego świata. Świat ten zagęścił się, skurczył i bez wątpienia bez odpowiedzialności i troski zmierzał będzie do katastrofy.

O ile nowy materializm Karen Barad jako koncepcja ontologiczno-epistemologiczna wsparta wiedzą fizyczną jest na ogół przyjmowany jako interesujący i szczególnie inspirujący przy okazji mierzenia się z konsekwencjami zagrożeń ekologicznych, jak i współoddziaływania materii/biologii na formę i treść ludzkiego myślenia, o tyle w odniesieniu do nauki o polityce jawi się być problematyczny. Jak bowiem można rozumieć politykę, jeśli materia staje się aktywną częścią procesów materializacji? Jak można dokonywać zmian w świecie, jeśli także i innym bytom przyznamy sprawstwo i dynamizm? Czy indeterminizm i nieprzewidywalność wynikający z tych procesów interakcji nie czyni projektów społecznych niemożliwymi? Aczkolwiek z drugiej strony pojawia się również pytanie, czy ta niemożliwość nie jest przypadkiem niezamierzonym, acz symbolicznym znakiem czasu, zbieżnym z kryzysem koncepcji obywatelstwa? Zamiast wspólnotowego aspektu obywatelstwa obserwować bowiem możemy w ostatnim czasie radykalizację życia politycznego, odradzania się partykularyzmów i tożsamości budowane w opozycji do innego.

${ }^{45}$ K. Barad, Erasers and erasures: Pinch's unfortunate 'uncertainty principle', „Social Studies of Science" 2011, no. 41(3), s. 450. 


\section{Bibliografia}

Arendt H., Kondycja ludzka, Warszawa 2000.

Barad K., Diffracting Diffraction: Cutting Together-Apart, Paralax 2014.

Barad K., Erasers and erasures: Pinch's unfortunate 'uncertainty principle', „Social Studies of Science" 2011, no. 41(3).

Barad K., Meeting the Universe Half Way, Quantum Physics and the Entanglement of Matter and Meaning, Durham, New York and London 2007.

Barad K., On touching - the inhuman that therefore $i$ am, differences, „A Journal of Feminist Studies" 2012, no. 23(3).

Barad K., Posthumanist performativity: Toward an understanding of how matter comes to matter, ,Signs: Journal of Women in Culture and Society” 2003, no. 28.

Batliwala S., Brown L.D., Transnational Civil Society: An Introduction, Bloomfield CT 2006.

Baylis J., Smith S., Globalizacja polityki światowej. Wprowadzenie do stosunków międzynarodowych, Kraków 2008.

Beck Ü., Społeczeństwo ryzyka. W drodze do innej nowoczesności, Warszawa 2002.

Beck Ü., Władza i przeciwwładza w epoce globalnej. Nowa ekonomia polityki światowej, Warszawa 2005.

Beck Ü., Gernsheim E., Miłość na odległość. Modele życia w epoce globalnej, Warszawa 2013.

Braidotti R., Po człowieku, thum. J. Bednarek, A. Kowalczyk, Warszawa 2013.

Braidotti R., Podmioty nomadyczne. Ucieleśnienie i różnica seksualna $w$ feminizmie współczesnym, tłum. A. Derra, Warszawa 2009.

Brown L.D., Creating Credibility: Legitimacy and Accountability for Transnational Civil Society, Bloomfield CT 2008.

Castells M., The power of Identity, Oxford 2013.

Castells M., Sieci oburzenia i nadziei. Ruchy społeczne w erze internetu, Warszawa 2013.

Castells M., Siła tożsamości, Warszawa 2008.

Castells M., Społeczeństwo sieci, Warszawa 2007.

Castells M., The Rise of Network Society, Oxford 2000.

Castells M., Władza komunikacji, Warszawa 2013.

Darendorf R., Zagrożone społeczeństwo obywatelskie, [w:] Europa i społeczeństwo obywatelskie. Rozmowy w Castel Gandolfo, red. K. Michalski, Kraków 1994.

De Landa M., Philosophy and Simulation: The Emergence of Synthetic Reason, London and New York 2011.

Dryzek J., Souvereign Virtue: The Theory and Practice of Equality, Cambridge 2000.

Dumała A., Uczestnicy transnarodowi-podmioty niezależne czy kontrolowane przez państwa?, [w:] Państwo we współczesnych stosunkach międzynarodowych, red. E. Haliżak, I. Popiuk-Rysińska, Warszawa 1995.

Dybel P., Wróbel S., Granice polityczności. Od polityki emancypacji do polityki życia, Warszawa 2008.

Etzioni A., From Empire to Community: A New Approach to International Relations, New York 2004. 
Florini A., The Third Force: The Rise of Transnational Civil Society, Tokyo and Washington 1999.

Gadamer H.G., Prawda i metoda. Zarys hermeneutyki filozoficznej, Kraków 1993.

Hannerz U., Powiazania transnarodowe. Kultura, ludzie, miejsca, Kraków 2006.

Held D., Global Covenant. The Social Democratic Alternative to the Washington Consensus, Cambridge 2004.

Held D., Global Transformations. Politics, Economics and Culture, Cambridge 1999.

Hyży E., Dzielenie się światem. Nowy feministyczny realizm w ujęciu Karen Barad, https:// www.academia.edu/28271247/Dzielenie_si\%C4\%99_\%C5\%9Bwiatem.Nowy_ feministyczny_realizm_w_uj\%C4\%99ciu_Karen_Barad.pdf(dostęp 10.03.2017).

Iriye A., Global Community: The Role of International Organizations in the Making of the Contemporary World, Berkeley 2002.

Kaldor M., The Global Civil Society. An Answer to War, Cambridge 2003.

Karwat M., Rodzaje teorii w polityce, [w:] Czym jest teoria $w$ politologii, red. Z. Blok, Warszawa 2011.

Kean J., Global Civil Society?, Cambrigde 2003.

Koselleck R., Trzy światy obywatelskie? Wprowadzenie do porównawczej semantyki społeczeństwa obywatelskiego w Niemczech, Anglii i Francji-zarys dziejów teorii, [w:] Europa i społeczeństwo obywatelskie. Rozmowy w Castel Gandolfo, red. K. Michalski, Kraków 1994.

Meillassoux Q., After Finitude. An Essay on the Necessity of Contingency, New York 2008.

Meillassoux Q., The Number and the Siren, New York 2012.

Pietrzyk-Reeves D., Idea społeczeństwa obywatelskiego, Torun 2012.

Seters P., Aproaching Global Civil Society, [w:] Critical Mass, The Emergence of Global Civil Society, eds J.W. Walker, A. Thompson, Waterloo 2008.

Singer P., One World: The Ethics of Globalization, New Haven 2002.

Taylor Ch., Kiedy mówimy społeczeństwo obywatelskie, [w:] Europa i społeczeństwo obywatelskie. Rozmowy w Castel Gandolfo, red. K. Michalski, Kraków 1994.

Walzer M., Spór o społeczeństwo obywatelskie, [w:] Ani książę, ani kupiec. Obywatel. Idea społeczeństwa obywatelskiego w myśli współczesnej, red. J. Szacki, Kraków 1997.

Walzer M., Toward a Global Civil Society, New York 1995. 
Эдита Петиак

\section{Современные теории гражданского общества через призму нового материализма}

Статья посвящена современным теориям гражданского общества в региональном,глобальном и транснациональном масштабе, что является основой отсылки к одному из наиболее интересных современных направлений в гуманитарных науках — концепции нового материализма. За основу предложенной в статье классификации принят, предложенный Рейнхардтом Косселецким, критерий расширения гражданских прав.

Ключевые слова: общество, гражданские права, новый материализм, гражданское общество.

\section{Edyta Pietrzak}

\section{Contemporary theories of civil society with reference to the concept of new materialism}

The article discusses contemporary theories of civil society at the local, global and transnational level with reference to one of the most interesting modern trends in humanities - the concept of new materialism. The proposed classification has been based on the criterion of civil rights expansion suggested by Reinhardt Koselleck.

Keywords: citizenship, civil rights, new materialism, civil society. 